\title{
TEACHING THE NATURE OF SCIENCE THROUGH STORYTELLING: SOME EMPIRICAL EVIDENCE FROM A GRADE 9 CLASSROOM
}

\author{
Yannis Hadzigeorgiou \\ Professor, School of Education, University of the Aegean \\ Associate Director, IERG, Simon Fraser University
}

\begin{abstract}
The instructional question of how to teach ideas about the nature of science effectively has been a challenge, but, according to the literature, explicit teaching appears to be the best way. However, the use of narratives, which incorporate actual events from the history of science, can also help illustrate the human and the larger socio-cultural context in which scientific knowledge was developed. Such context facilitates students' understanding of science as a human endeavour, which is characterized by successes and failures as well as problems and struggles. It makes them aware of the fact that scientific knowledge is tied to human hopes, expectations, passions, and ambitions. Moreover, the use of narratives can help students understand such ideas as: scientific knowledge, while durable, is tentative and subject to revision, people of both sexes and from many countries have contributed to the development of science, science is a creative activity, science has a sociocultural dimension, and also that there is not a standard scientific method, as scientists use a variety of approaches to explain the natural world. A recent empirical study provides evidence that such ideas can indeed be understood by 9 th graders.
\end{abstract}

Keywords: Nature of Science (NOS), Narrative, Storytelling, School Science 


\section{Introduction: The importance of NOS ideas}

Over the last two decades considerable attention has been paid to the importance of understanding the nature of science (NOS). This attention is due to recent scholarship in the philosophy, history and sociology of science. In line - but not in total agreement - with the postmodernist critique of science, this scholarship has helped change our view of scientific knowledge as something absolute, and of scientific inquiry as a process that is primarily concerned with the discovery of truth. Contrary to such views, scientific knowledge is taken to be provisional and problematic, and scientific inquiry is approached as a process which aims at improving our existing knowledge of the world rather than at arriving closer to truth. The importance for students to understand NOS ideas can be seen in the fact that, while learning science in the 1970 s and 1980 s was mainly about learning science content and science process skills, more recently the focus has been on science content, the nature of science and scientific inquiry (Trefil, 2003; Schwartz et al. 2004; Matthews, 2015). Indeed, the teaching of NOS ideas is considered one of the most important goals of school science education.

But why is teaching NOS ideas important? First of all, because science is often misrepresented, in both the media and in public discourse. For example, one can find many inaccuracies that are allowed by the media (e.g., stem cell research, nutrition), and can also see that people very often conflate a hypothesis with evidence. And second, because classroom teaching can overemphasize the "what of science" (i.e., what we know) at the expense of the "how of science" (i.e., how we come to know). As a result, many students view science as a boring enterprise, which deals with the accumulation of facts about the natural world (Hadzigeorgiou, 2014; 2016; Hadzigeorgiou \& Konsolas, 2001).

As Bruner (1996) has pointed out, our instruction in science from the start to the finish should be mindful of the lively processes of science making, rather than being an account only of 'finished science' as represented in the textbook, in the handbook, and in the standard and often deadly 'demonstration experiment. He went on to say that the goal of narrative instruction is not to subvert the idea of objective knowledge so much as to emphasize the process - oriented nature of science, to shift the focus from an exclusive concern with "nature-as-out-there" to a concern with the search for nature - how we construct our model of nature (Bruner, 1996). It is not therefore a coincidence that over the last two decades considerable attention has been paid to the importance of understanding the nature of science.

Bruner's $(1986,1996)$ ideas are in line with recent developments in the philosophy, history, and sociology of science, and have helped change our view of scientific knowledge as something absolute, and of scientific inquiry as a process that is primarily concerned with the discovery of truth. (Even though such a view of scientific knowledge can be traced back to the birth of the theories of relativity and quantum physics, science educators began to seriously consider it with the development of the so-called 'constructivist' perspective.) Contrary to such views, scientific knowledge is taken to be provisional and problematic, and scientific inquiry is approached as a process which aims at improving our existing knowledge of the world rather than at arriving closer to truth (Hadzigeorgiou, 2016). 
Such a view of scientific knowledge concurs with Kieran Egan's notion of 'ironic understanding'. Indeed, according to Egan (1997), 'ironic understanding' is a kind of understanding that involves the "mental flexibility to recognize how inadequately flexible are our minds, and the languages we use, to the world we try to represent in them" (p.155). And it is this recognition - this Socratic stance towards knowledge that makes the notion of truth questionable, and, in fact, unattainable.

And it is quite interesting to note that 'ironic understanding', while it follows the development of conceptual understanding (or according to Egan's terminology 'philosophic understanding), provides a more complete view of what it means to have knowledge of the world, in the same way that knowledge of the nature of science, as a complement to science content knowledge and science as inquiry, provides a more complete view of science as a human endeavour.

In this paper I am going to discuss briefly the idea and the features of narrative as well as and its role in school science education, and then focus on a specific role, that is, narratives as tools for introducing ideas from the nature of science. I will then present some empirical evidence from an action research project that provides support for the effectiveness of narratives as such tools.

\section{The notion of narrative and its role in science education}

It would be a truism to state that over the last two decades there has been an emphasis on narrative in our culture. The reason is that it has been found that narrative is central to our cognitive activities, to historical thinking, to psychological analysis and practice, to political critique and praxis. It has also been found that narrative is crucially important in the formation of an individual's sense of identity. And in educational research, narrative has been used as a medium of data representation and as a guide for the development of methodologies (Hadzigeorgiou, 2016). This need for using narratives in such a variety of fields and human activities can be linked to an impulse that seems to be primordial. According to Bell (1991), "The shaping of experiences by narrative, indeed the very impulse to tell stories, may suggest primordial but subliminal processes underlying even the apparently independent planes of reason or evidence (p.172).

Defining a narrative, as Klassen and Froese-Klassen (2014) point out, is crucial not only for clarification but also for ascertaining whether writing that purports to be narrative can indeed be characterized as narrative. The notion of narrative, according to a recent analysis by Klassen and Froese-Klassen (2014), is quite broad, and it does not have a categorical definition in the literature (see also Avraamidou \& Osborne, 2009), in contrast to the literary notion of story.

More often than not, the terms "narrative" and "story", are used interchangeably. However, for pedagogical purposes it is crucial, but at the same time easy, to distinguish between the two notions: a narrative can be considered a flow of events associated with a theme/idea, while a story can be considered a sequence of these events to create meaning. And the sequencing of events is the most distinguishing characteristic of stories. A collage, for example, can be used to generate a narrative but not a story, unless the events that the various photos describe or give rise to (through an interpretation) are deliberately placed in a sequence, so there is a beginning, a middle part, and an end (see Hadzigeorgiou, 2016). Thus narrative is a more general term, which subsumes that of story. 
A narrative is characterized by its so-called elements or features. Klassen and FroeseKlassen (2014) have provided an evaluative list of narrative features which can used to evaluate the effectiveness of a narrative from an instructional perspective. These are: Character(s) taken from history of science, Actions that are consistent with the historical record, Situations or States, Consequential coherence of the characters' actions, Past time, Plot structure with rising action and climax, Critical choice made by the main character, Appropriate science and NOS content.

In the context of school science education, a narrative can perform specific functions. Hadzigeorgiou (2016) has summarized these as follows: a) The humanization of scientific knowledge, b) The introduction of ideas from the nature of science, c) The encouragement and development of romantic understanding, d) The introduction to scientific inquiry, e) The presentation of thought experiments, and f) The development of environmental awareness. These functions certainly subsume the most frequently cited ones, like, illustration, contextualization, engagement, and meaningfulness, and they represent the pedagogical importance of narrative in science education. The introduction of NOS ideas through narrative deserves particular attention, which is discussed in the next section.

\section{Teaching NOS ideas through narrative}

The instructional question of how to teach NOS ideas effectively has been a challenge, but, according to the literature, explicit teaching appears to be the best way (Lederman, 1998). However, the use of narratives, which incorporate actual events from the history of science, can also help illustrate the human and the larger socio-cultural context in which scientific knowledge was developed. Such context facilitates students' understanding of science as a human endeavour, which is characterized by successes and failures as well as problems and struggles. It makes them aware of the fact that scientific knowledge is tied to human hopes, expectations, passions, and ambitions. Moreover, the use of narratives can help students understand such ideas as: scientific knowledge, while durable, is tentative and subject to revision, people of both sexes and from many countries have contributed to the development of science, science is a creative activity, science has a sociocultural dimension, and also that there is not a standard scientific method, as scientists use a variety of approaches to explain the natural world (Hadzigeorgiou, 2016).

The narrative perspective on science is premised on the fact that scientific theories are fundamentally story-like, in the sense that they rely on metaphors, analogies, and interpretive frameworks (Hadzigeorgiou, 2001; Hadzigeorgiou \& Stefanich, 2001; Norris et al., 2005; Corni et al. 2010; Hadzigeorgiou et al., 2012; Klassen \& FroeseKlassen, 2014).

Certainly, there are limitations as regards the use of narrative in science education (Hadzigeorgiou, 2016). For example,

- Narrative explanations are more suitable for the historical sciences (e.g., geology, cosmology astrophysics) and for unique events.

- It is difficult to create narratives for all phenomena and for all science concepts because of the need to use deductive-nomological explanations. 
- Descriptive explanations, while they can be presented in a narrative form (through the use of anthropomorphism), are more suitable for young children.

- Scientific ideas (e.g., concepts, laws), in order to be understood, need to be applied in a wide variety of situations.

- There is a very limited number of empirical studies that provide evidence of the effectiveness of narrative on understanding science concepts.

These limitations do not imply that narratives cannot be used in the case of adolescents or adults. Nor do they imply that narratives cannot be used to explain scientific concepts. What they do imply though is that the creation of narratives for describing a physical phenomenon and explaining a scientific concept (e.g., current electricity as flow of electrons, photosynthesis, radioactivity, electromagnetic radiation) requires attention and creativity, so that all the narrative features all included. For it is one thing to believe that the narrative mode of thinking opens up many, and perhaps endless, possibilities in the context of school science education, and another thing to create narratives that are effective in helping students (of all ages) to understand science ideas. True, there are excellent examples of narratives that provide historical information about the development of a scientific field or the development that took place within that field. For example, In The Body of the Artisan, Pamela Smith provides astonishingly vivid examples of the synergy among craft, art and science, which took place during the Scientific Revolution. But this is different form the evolution of the scientific ideas themselves.

Nevertheless, it deserves to be noted that the narrative mode of thinking has been considered a bridge too science. Indeed, if all people understand how to think in stories, then the narrative mode of thinking (i.e., the natural, the default mode of thinking) can be used as a bridge to the paradigmatic mode of thinking, which can facilitate the "passage" to science. This passage to science is facilitated because (Egan, 1990; Stinner, 1995; Hadzigeorgiou, 1999, 2016; Hadzigeorgiou \& Stefanich, 2001):

- Help students become emotionally involved

- Help students imagine that they themselves can do science

- Help students develop a "Romantic Understanding" of science

- Introduce students to scientific inquiry

- Help students develop an understanding of NOS

In view of the above, it would be a truism to say that any science story should portray the nature of science. Students should be helped, by listening to a science story, to become aware of this nature. This can happen if the plot (the events) of the story and the ideas embedded in it portray scientists and their endeavour as they really are. In such case, students are not just helped to view science as a human endeavour; they are helped to see and understand the tentative, provisional nature of scientific knowledge, and, most importantly, both the scientists' successes and failures (see Heering, 2010; Solomon, 2002). There is evidence that "historical narrative is a 'good opener' to teach the nature of science” (Schiffer \& Gueria, 2015, p. 409).

In regard to presenting science as it is, that is, with both its successes, its failures, and its problems (i.e., practical, intellectual), a teacher does not just encourage engagement with science; he or she helps students to see the scientists portrayed in the story as real human beings (and not as super humans with exceptional 
intellectual powers), and thus help them to identify with those scientists. This identification refers to the case in which a student identifies with the scientist him/herself and/or simply to the case in which the student simply does science. This issue of identification, namely 'to be a scientist' or 'to do science' is an important one but it is beyond the scope of the present paper.

In regard to the tentative, provisional nature of scientific knowledge, the plot of the story should incorporate real events from the history of science that document: a) the change of scientific ideas over the course of time, b) the existence of various (competing or complementary) theories for explaining a natural phenomenon, and c) the irrationality of scientific progress.

Apparently, stories that can document the change of scientific ideas are easy to find in the history of science, which, in fact, testifies to the growth of scientific knowledge, as a result of the reconsideration, modification or rejection of previous ideas (e.g., The Story of Motion: from Aristotle to Galileo and Newton; The Story of Heat: From Joseph Black and Count Rumford to Robert Mayer and James Joule; The Story of Gravity: from Newton to Einstein). It is more difficult, however, to document the irrationality of science and scientific progress. The reason may very well be that the notion of irrationality does not appear to describe science, which seems to be a rational endeavour. And it really is, unless one becomes aware of the fact that there are events in the history of science that testify to the downright rejection of "crazy" or irrational ideas, which, however, ended up being very rational, since they now count as standard scientific knowledge .

Even though an "anarchist theory of science" (Feyerabend, 1993) can help one understand the irrational character of scientific progress, with younger students this can become easier through stories that include historical events documenting the initial rejection of 'crazy' or irrational ideas, but which are now accepted as scientific ideas. These events can show that judging an idea as irrational or impossible (at the time of its conception) does not help scientific progress. The important idea that needs to be infused into the plot of the story is that the certainty with which certain scientists of the past defended the rejection of some ideas was eventually shattered.

Heering (2010) argues that in order for the story to help students understand the nature of science, four ideas need particular attention and, of course, need to be included in, or emerge from, the plot of the story: (a) Scientific knowledge, while durable, has a tentative character, (b) People from all cultures contribute to science, (c) Scientists are creative, and (d) Science is part of social and cultural traditions." The stories about the development, for example, of the concepts of force and motion, gravity, heat, and light, do help students understand all of the above ideas. The story about the heat, in particular, can show that the development of scientific knowledge is the result of the contribution of many scientists (e.g., Joseph Black from Scotland, Benjamin Thomson or Count Rumford from America, Humphrey Davy from England, Jacque Charles form France, Robert Mayer form Germany, James Joule from America) and thus dispel the myth of the "lone-star scientist". However, such a story shows students another important aspect - perhaps an indirect consequence or rather byproduct of scientific work - that is not often associated with the nature of science. This aspect refers to the recognition that a scientist truly deserves. For example, Joule's contribution to the discovery of the nature of heat had been recognized more in America and Britain than in Continental Europe, while exactly 
the opposite happened with Mayer's contribution. Of course, twenty years later that issue was finally settled, as it was recognized that both scientists deserved credit (Wilson, 1965). But with Daniel Bernoulli, things are different, since his pioneering work that made a major contribution to our understanding of heat as molecular motion remained unrecognized. His work was well ahead of his time, not, of course, because he was not recognized as a scientist, but because of the way science develops:

Bernoulli's work was at least a century ahead of his time. His theories came in period when caloric was the most popular explanation of heat, and he went unheeded, when in his long-neglected work, Hydrodynamica, he turned his back on caloric by saying that "heat may be considered as an increasing internal motion of the particles. Indeed, Bernoulli's postulation was made more than 100 years prior to Joule's final statement on the equivalence of heat and motion. (Wilson, 1965, p. 53)

It should be noted that storytelling, perhaps more than any other approach, can help present to the students a more realistic image of scientific inquiry, since it portrays the scientists' life events and their experiences and how they (life events, experiences) are associated with scientific knowledge. Although inquiry science can help students become aware of the tentative nature of knowledge (i.e., by becoming aware of the fact that there are so many parameters involved in the investigation of a problem that they can never be absolutely certain of the result of their study, or that there are so many factors to be considered in a given investigation that knowledge of all those factors is impossible and hence our knowledge is incomplete), storytelling represents a direct approach to learning about the nature of scientific knowledge - in line, in my view, with the one recommended by Lederman (1998). It is a direct approach because it explicitly presents ideas - in addition to the tentative nature of scientific knowledge - that only through storytelling can become understood by students, especially young children.

In creating narratives, the following NOS ideas (see Kind \& Kind, 2007; McComas, 1998) can be embedded into, or emerge from, the plot of the story or narrative:

- Science produces, demands and relies on empirical evidence

- Experiments are not the only route to knowledge

- Science uses both inductive reasoning and hypothetico-deductive testing

- Scientists make observations and produce inferences

- There is no single step-by-step scientific method by which all science is done

- Science has a creative component

- Observations, ideas and conclusions in science are not entirely objective

- Historical, cultural and social influences impact the practice and direction of science

- Scientific knowledge is tentative, durable and self-correcting

It is important to point out that the Next Generation Science Standards (NGSS) have included the following NOS ideas, which must be learned by the students (Hadzigeorgiou, 2016):

- Scientific knowledge is based on empirical evidence

- Scientific knowledge is open to revision in light of new evidence 
- Scientific Investigations use a variety of methods

- Science is a way of knowing

- Science is a human endeavor

The question, of course, is to what extent can the above NOS ideas be learned through the use of narratives? The empirical evidence presented in the next section provides an answer to this question.

\section{Empirical evidence from an action research project}

In the context of a 9th grade classroom with 25 students, a science teacher conducted action research (Hadzigeorgiou, 2012) in order to investigate the degree to which narrative/storytelling can help students learn NOS ideas. To this end, he incorporated the following five NOS ideas:

- Science is a human endeavour.

- Scientific knowledge, while durable, is tentative.

- People from a variety of nations can contribute to science.

- Science is a highly imaginative/creative activity.

- Science has a socio-cultural dimension.

And the stories he used - in accordance with the mandated curriculum and the science content to be covered during the school year - in order to illustrate these ideas were the following:

- MOTION: From Aristotle to Galileo and Newton.

- HEAT: From Joseph Black (Scotland), Benjamin Thomson or Count Rumford (America), to Humphrey Davy (England), Jacque Charles (France), Robert Mayer (Germany), and James Joule (America).

- COMBUSTION: From Stahl's phlogiston theory and Prtistley's diphlogistated air to Lavoisier's oxygen.

- CURRENT ELECTRICITY: The Galvani-Volta Controversy and the work of Michael Faraday

- FOSSILS: The work of Robert Hooke

- ATOM: From Thomson to Rutherford and Bohr.

- GEOLOGICAL CHANGES: From Neptunism to Humboldt's earth movements, and H.H Hess's plate tectonics.

The assessment of the effectiveness of the aforementioned stories took place immediately after the telling of the stories, and at the end of the school year. The teacher, after the telling of each story, asked students to think and write "what things about science" they thought they learned through the story. Some of the ideas were easy to emerge from the narration of the story, while some other ideas required reflection on the part of the students. The NOS ideas and the number of students who identified them were as follows ( $\mathrm{R}$ stands for 'after reflection' with the teacher's encouragement):

- Scientific knowledge can change in light of new evidence. $(\mathrm{N}=23)$

- Scientific knowledge is the product of the work of many scientists from many countries. $(\mathrm{N}=23)$

- Scientists can disagree on the correct explanation of an idea. $(\mathrm{N}=24)$

- Scientists rely on other scientists $(\mathrm{R})(\mathrm{N}=20)$ 
- Science is an imaginative/creative activity $(\mathrm{R})(\mathrm{N}=17)$

- There is no such a thing as a "standard scientific method" (R) $(\mathrm{N}=16)$

- There are not always successes but also failures. $(\mathrm{N}=19)$

- Science has a socio-cultural dimension (i.e., is influenced by social and cultural factors). (R) $(\mathrm{N}=8)$

The second assessment that focused on students' ability to remember NOS ideas at the end of the school year gave the following results:

- Scientific knowledge can change in light of new evidence $(\mathrm{N}=22)$

- Scientific knowledge is the product of the work of many scientists from many countries $(\mathrm{N}=21)$

- Scientists can disagree on the correct explanation of an idea $(\mathrm{N}=20)$

- Scientists rely on other scientists $(\mathrm{N}=18)$

- There is not a single and universal scientific method $(\mathrm{N}=15)$

\section{Conclusion}

In looking at these numbers, it becomes quite evident that narratives/stories can be very effective in helping students learn NOS ideas, if the latter have been explicitly or implicitly embedded into their plot. And the message that this empirical evidence sends to the science education community is that narrative/storytelling is indeed an effective teaching-learning tool, which can be used convey not only science content ideas, but also ideas about science as a human endeavour and as a social tradition. 


\section{References}

Avraamidou, L., \& Osborne, J. (2009). The role of narrative in communicating science. International Journal of Science Education, 31, 1683-1017.

Bruner, J. (1986). Actual minds, possible worlds. Cambridge, MA: Harvard University Press.

Bruner, J. (1996). The culture of education. Cambridge, MA: Harvard University Press.

Corni, F., Gilberti, E., \& Mariani, C. (2010). A story as innovative medium for science education in primary school. Retrieved March 12, 2015 from https://personale.unimore.it/rubrica/pubblicazioni/corni.

Egan, K. (1990). Romantic understanding. Chicago: University of Chicago Press.

Egan, K. (1997). The educated mind. How cognitive tools shape our understanding. Chicago: University of Chicago Press.

Feyerabend, P. (1993). Against method. London: Verso.

Hadzigeorgiou, Y. (2001). The Role of Wonder and «Romance» in Early Childhood Science Education. International Journal of Early Years Education, 9, 63-69.

Hadzigeorgiou, Y. (2005). On humanistic science education. Eric Document (ED506504)

Hadzigeorgiou, Y. (2012). Narrative as a tool to teach NOS ideas. Unpublished paper. University of the Aegean, Rhodes, Greece.

Hadzigeorgiou, Y. (2014). Reclaiming the value of wonder in science education. In K. Egan, A. Cant., \& G. Judson (Eds.), "Wonder-full education": The centrality of wonder in teaching and learning across the curriculum (pp. 40-65). New York, London: Routledge.

Hadzigeorgiou, Y. (2016). Imaginative science education: The central role of imagination in science education. Cham, Switzerland: Springer International.

Hadzigeorgiou, Y. \& Konsolas, M. (2001). Global problems and the curriculum: Toward a humanistic and constructivist science education. Curriculum \& Teaching, 16, 29-39.

Hadzigeorgiou, Y., \& Stefanich, G. (2001). Imagination in science education. Contemporary Education, 71, 23-28.

Hadzigeorgiou, Y., \& Fotinos, N. (2007). Imaginative thinking and the learning of science. Science Education Review, 6, 15-22.

Hadzigeorgiou, Y., Klassen, S., \& Froese-Klassen, C. (2012). Encouraging a 'romantic understanding' of science: The effect of the Nikola Tesla story. Science \& Education, 21, 1111-1138.

Heering, P. (2010). False friends: What makes a story inadequate for science teaching? Interchange, 41, 323-333.

Kind, P., \& Kind, V. (2007). Creativity in science education: perspectives and challenges for developing school science. Studies in Science Education 43, 1-37. 
Klassen, S., \& Froese-Klassen, C. (2014). Science teaching with historically based stories: Theoretical and practical perspectives. In M. Matthews, (Ed.), International handbook of research in history and philosophy for science and mathematics education (pp. 1503-1529). Berlin: Springer.

Lederman, N. (1998). The state of science education: Subject matter without context. Editorial. Electronic Journal of Science Education,3, 2.

Matthews, M. (2015). Science teaching: The contribution of history and philosophy of science. New

McComas, W. (1998). The nature of science in science education: Rationales and strategies. Dordrecht, The Netherlands: Kluwer Academic Publishers.

Norris, S., Guilbert, S., Smith, M., Hakimelahi, S., \& Phillips, L. (2005). A theoretical framework for narrative explanation in science, Science Education, 89(4), 535554 .

Osborne, J., Collins, S., Ratcliffe, M., Millar, R. \& Duschl, R. (2003). What "ideasabout- science" should be taught in school? A Delphi study of the expert community. Journal of Research in Science Teaching, 40, 692-720.

Schiffer, H., \& Gueria, A. (2015). Electricity a vital force: Discussing the nature of science through historical narratives. Science \& Education, 24, 409-434.

Schwartz, R., Lederman, N., \& Crawford, B. (2004). Developing views on NOS in an authentic context. An explicit approach to bridging the gap between NOS and scientific inquiry. Science Education, 88, 610-640.

Smith, P. (2006). The body of the artisan. Chicago: University of Chicago Press.

Solomon. J. (2002). Science stories and science texts: What can they do for our students? Studies in Science Education, 37, 85-106.

Stinner, A. (1995). Contextual settings, science stories and large context problems: Toward a more humanistic science education. Science Education, 79, 555-581.

Trefil, J. (2003). The nature of science: an A-Z guide to the laws and principles governing the universe. Boston, Mass: Houghton-Mifflin.

Wilson, M. \& The Editors of Life. (1965). Energy. The Netherlands: Time-Life International. 